\title{
¿Enfermedades sociales o patologías individuales?
}

El debate actual en tomo al problema de la violencia pasa necesariamente por una tipificación. Es harto sabido ya que para una comprensión más cabal del fenómeno conviene diferenciar la violencia política de la violencia intrafamiliar, por ejemplo. Así, los analistas sociales han establecido una serie de modos en los que las conductas violentas tienden a manifestarse. Esta discusión toca de manera directa a El Salvador en tanto éste se disputa con Colombia el primer lugar en niveles de violencia. Las últimas dos décadas de la historia salvadoreña han estado marcadas por dos formas exteriorizadas de violencia: la violencia política y la violencia delincuencial. Si durante los años ochenta el acontecer nacional se hallaba determinado por el conflicto bélico, los años noventa han estado marcados por los problemas de seguridad pública.

Ésta es la tesis que anima a las investigaciones que continuamente se realizan en el país sobre violencia y las políticas que, mal que bien, se implementan $\longrightarrow$ intentan implementarse - para contrarrestarla. La idea parece ser que una vez superado el flagelo de la guerra, el nuevo enemigo por combatir - en materia de violencia- es la delincuencia. Ahora bien, eso es cierto, pero sólo relativamente. Que luchar por encontrar formas de minimizar la criminalidad debe ser prioridad de cientistas sociales y funcionarios gubernamentales es algo que difícilmente podría ser puesto en duda. El problema es que el énfasis que se ha hecho en el fenómeno delincuencial ha dejado de lado el interés y tratamiento de otras manifestaciones de violencia de igual o mayor importancia.

\section{Violencias "segundas"}

Nos referimos aquí a la violencia en el interior de la familia; a la violencia "de la calle", que vuelve vulnerable a cualquiera cada vez que sale de su casa (balas perdidas, accidentes de tránsito); y la violencia "de la cárcel”, a la que cualquiera que ingrese a un centro penal - por el motivo que fuere- está expuesto. Noticias truculentas sobre madres asesinas o torturadoras, padrastros u otros familiares pederastas, niños afectados de por vida por balas perdidas, muertos en accidentes de tránsito, casos de muerte, tortura y violación entre reos aparecen con alarmante frecuencia en los medios de comunicación y en las conversaciones casuales de los conocidos.

Lo preocupante aquí, más allá de los hechos en sí mismos, es el manejo que de ellos están haciendo la opinión pública y las autoridades. Cada vez que un menor es víctima de abuso o que un inocente muere atropellado por un conductor irresponsable, el hecho es inmediatamente particularizado. Detalles de lo ocurrido, fotos, nombres y apellidos de los involucrados acuden rápidamente a la prensa, la radio o la televisión para resaltar que fue una persona concreta quien padeció una situación también concreta. Ningún camino más fácil que éste para aislar los casos unos de otros, cimentando así la idea de que sólo ciertos desafortunados se ven envueltos en tragedias tales.

Afirmar que existe una política establecida deliberadamente para hacer parecer como casos aislados tragedias de este tipo sería descabellado. Lo que no lo es tanto es señalar que para los grupos en los que recae gran parte de la responsabilidad en el manejo de estos modos "secundarios" de violencia resulta bastante conveniente darles este carácter particular.

En primer lugar está el gobierno, siempre preocupado por vender al país como el más próspero 
de Centroamérica. Recordemos cuán difícil fue que Calderón Sol reconociera que la delincuencia constituye uno de los problemas más graves dél país; aun hoy las medidas que se han tomado para hacerle frente hacen dudar de qué tan sensible es esta administración ante lo mucho que el flagelo afecta a la población.

Aceptar que la violencia intrafamiliar y esos otros tipos de violencia, que en consideraciones serias sobre el fenómeno son continuamente soslayados, lejos de ser casos particulares son, al igual que la delincuencia, problemas sociales implicaría, por un lado, tener un punto más en contra de la visión utópica de El

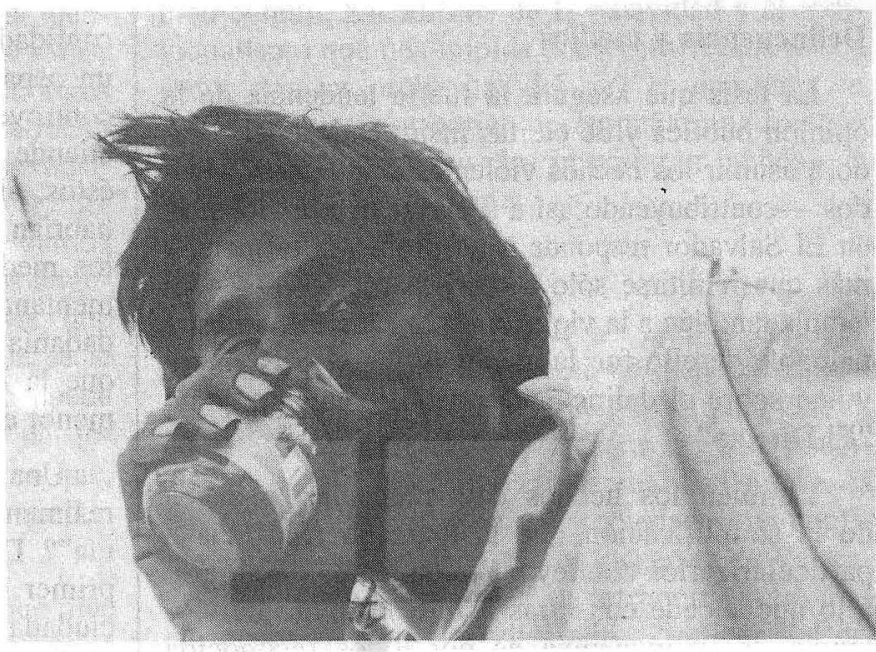
Salvador que el actual presidente ha querido transmitir, y por el otro, aceptar que existe un grave problema más por resolver.

En segundo lugar, está la sociedad civil. Empezar a observar las conductas patológicas de las familias, la forma psicópata en la que aquí se conduce y las costumbres que configuran el modus vivendi en las cárceles como comportamientos que responden a patrones sociales traería consigo la obligación de empezar a aceptar que vivimos en una sociedad enferma. $Y$ eso es algo que no muchos están dispuestos a reconocer. Si es la sociedad la que se encuentra enferma, entonces resulta que somos todos los que, en menor o mayor medida, participamos de esa enfermedad. Ya no se trataría de ciertas personas perturbadas, drogadas o alcoholizadas que andan por ahí convirtiendo en víctimas a otras que corrieron con muy mala suerte. Se trataría de que tanto en los actos de esos "perturbados" como en los daños que causen a sus víctimas, todos tendríamos una cuota de responsabilidad.

Recluir en centros especiales a aquellos individuos cuya conducta les impide relacionarse con otros "normalmente" es una costumbre milenaria. En determinadas circunstancias es indiscutible que tomar tal medida es necesario. Pero en una sociedad como la salvadoreña, en donde más de un individuo de conducta "anormal" es arrestado a diario, resulta cada vez más difícil seguir pensando en los hechos violentos como cuestión de individualidades. ¿Cuáles son los rasgos de nuestra sociedad que contribuyen a generar conductas tan aberrantes o irresponsables? Es la pregunta que

deberíamos empezar a hacernos, antes de pensar en la posibilidad de la pena de muerte u otras medidas coercitivas destinadas a aplacar los impulsos destructores de los "enfermos".

Es harto sabido que el antecedente psicológico de un pederasta es haber sido abusado durante su infancia, del mismo modo que los padres torturadores suelen haber sido torturados en su niñez. Cuando esas patologías degeneran en atrocidades como el ímpetu de una madre de asesinar a su hijo, es claro que esta madre padece de un trastorno mental. ¿Pero no existirán acaso condiciones sociales que potencian su patología? ¿Será encarcelarla la forma correcta de darle respuesta a su enfermedad? Con seguridad, una buena parte de los salvadoreños daría un sí a esa última interrogante. Se pierde de vista con mucha facilidad que la violencia es una espiral ascendente, en cuyo dinamismo participamos todos de algún modo u otro.

Un niño maltratado difícilmente dejará de ser maltratador. Si en su vida adulta su conducta lo lleva a la cárcel, ¿qué posibilidades reales tiene allí de reinsertarse a la sociedad? ¿No es, más bien, más factible que su patología lo conduzca a la muerte? Ahora bien, si casos como éste marcan la vida de un número de familias aún indeterminado pero sin duda escandaloso, ino estamos hablando de una sociedad enferma más que de enfermos aislados que es necesario marginar? Soslayar este hecho conviene a la buena salud de la conciencia colectiva y a las intenciones políticas del partido en el gobierno, ¿pero no será a larga, o no está siendo ya, contraproducente? 


\section{Delincuencia y medios}

La tesis que asegura la fuerte tendencia de la opinión pública y de ciertas instituciones del Estado a asumir los hechos violentos como casos aislados - contribuyendo así a soslayar que la violencia en El Salvador responde a un problema estructural más que remitirse sólo a casos particulares - contempla también a la violencia delincuencial. Muestra palpable de ello fue la atención que el país entero volcó sobre el delincuente juvenil conocido como "El Directo".

También los hechos delincuenciales padecen de la simplificación que la marcada tendencia a particularizarlos conlleva. Ciertamente, y contrario a lo que sucede con otras manifestaciones de violencia, la delincuencia es por todos reconocida como un problema social, pero sólo en cuanto que afecta a la mayor parte de la población y no en tanto que es la estructura social misma la que facilita el surgimiento de personas que delinquen. Es decir, en el discurso oficial, la delincuencia ha alcanzado el estatus de "problema social" porque es predominantemente considerada desde el punto de vista de las víctimas y no del de los victimarios. Para los medios de comunicación y para los entes encargados de impartir justicia no suele existir más que un sujeto —el delincuente- que asesina $o$ viola y que, por ende $-y$ ay de quienes se atrevan a cuestionar esa obviedad-, merece ser castigado con las más duras penas.

Ése es justamente el caso de Gustavo Adolfo Parada Morales, alias "El Directo". Con él ha quedado demostrado, una vez más y de manera contundente, el poder que tienen los medios para manipular la opinión de toda una nación. Nadie podría negar que el hecho de que un delincuente juvenil de alta peligrosidad se fugue de su centro de rehabilitación es grave y amerita cobertura periodística. Lo que sí puede ponerse en duda es si la manera en que se trató el caso haya sido la más adecuada. Desde el inicio, la polémica empezó a girar alrededor del aspecto legal. La mayor parte de los comentaristas y redactores están de acuerdo en que la Ley del Menor Infractor es demasiado blanda y, por consiguiente, está poco ajustada a la realidad de una sociedad en donde los menores infringen continuamente la ley.

Amparados en lo inadecuado que, según su criterio, resulta dicho precepto, prensa, radio y televisión se dieron a la tarea de publicar la mayor cantidad posible de fotos del imputado y de crear un aspaviento pocas veces visto antes. Ahora la controversia se centra en el interés de la juez que atiende el caso en demandar a los medios, pues éstos, al hacer público el rostro. de "El Directo", habrian violado la normativa. Ante tal posibilidad, los medios han puesto el grito en el cielo argumentando que, ante los peligros que corre la ciudadanía con jóvenes asesinos como éste, pretender que la Ley garantice la "intimidad personal" del menor es un sin sentido.

Una primera pregunta salta a la vista: iinteresa realmente a los medios "el bienestar de la ciudadanía"? Difícilmente se podría afirmar que sí. En primer lugar, ¿en dónde estaba ese interés por la ciudadanía cuando, durante los crudos años de la década pasada, asesinos y torturadores hacían de las suyas a lo largo y ancho del territorio salvadoreño sin que ninguno de los medios de comunicación se pronunciara al respecto? Eran otros tiempos, dirán muchos para contrarrestar este cuestionamiento. Tiempos que, según parece, justificaban el hecho de que los mismos directores de cadenas de radio, prensa y televisión, que ahora claman a los cuatro vientos el derecho de la ciudadanía a estar informada, se callaran deliberadamente los nombres de los responsables de horrendas masacres, el paradero de los niños desaparecidos y todo tipo de violaciones sistemáticas a los derechos humanos.

En segundo lugar, no se ve nada claro que a los mass media les importe proteger a la ciudadanía cuando, sin ningún escrúpulo, publican a diario imágenes de niños maltratados completamente desnudos o preguntan a una mujer que acaba de ser víctima de una violación cosas tan absurdas como: “¿cómo se siente?". De la misma manera, la preocupación de los medios por el bien común resulta dudosa cuando a otros crímenes tan condenables, como los que se le atribuyen a "El Directo", no les dan la misma cobertura debido a que personalidades influyentes se hallan involucradas en ellos. Si los rotativos y demás medios de difusión están tan interesados en defender los derechos de la población, ¿no deberían dar igual cobertura a todos los hechos delictivos? ¿Por qué unos parecen tener para ellos más relevancia que otros?

La respuesta a esta última interrogante es sencilla: sensacionalismo. Antes que la bienintencionada preocupación por la ciudadanía está el interés impostergable de ensanchar las arcas. En el caso 
concreto en cuestión, que la población debía identificar el rostro del joven delincuente para tomar precauciones y contribuir a su captura es un argumento válido y sostenible, pero para ello hubiera bastado una foto de tamaño regular o una exposición de algunos segundos en televisión. No era necesario llenar las primeras páginas de los diarios con fotografías del acusado desde todos los ángulos posibles durante tres días. Por otra parte, que la fuga de "El Directo" y los crímenes que se le adjudican causen aspaviento es lógico; no puede ser menos que alarmante que una persona tan joven haya cometido diecisiete asesinatos y que, además, la probabilidad de que sus delitos queden impunes sea tan grande.

Pero, ¿no sería más propio de alguien, que dice estar interesado por el bienestar de los salvadoreños, indagar sobre las motivaciones de los delincuentes juveniles o realizar investigaciones que permitan ir vislumbrando modos de prevenir y enfrentar este tipo de casos, más que dedicarse a explotar el morbo de la audiencia con el único fin de no quedarse atrás en la dura competencia periodística?

No es satanizando a cada delincuente como los medios de comunicación van a contribuir a mejorar la crítica situación de la seguridad pública en El Salvador. No es explotando la tendencia general de la gente a quedarse en el lado superficial y llamativo de las cosas como esas entidades encargadas de informar van a cumplir la función pedagógica que les es inherente y que debería ser anterior a sus intereses económicos. No es tratando los hechos como casos aislados como los periodistas van a encarnar el rol crítico y comprometido con la sociedad que su oficio les demanda.

Mientras los mass media continúen cayendo en la superficialidad y el sensacionalismo que cada vez les es más característico, difícilmente podrán aportar algo a la democratización del país y al bien común. Sacudimos de la pasividad y el individualismo que nos impide comprometernos más a fondo con los problemas del país es una tarea en la que los medios podrían desempeñar una función decisiva, si los colones les importaran menos que el bienestar de la mayoría.

\section{Consideraciones}

No se trata de justificar a quienes cometen atrocidades apelando a la cuota de responsabilidad que todos tenemos en la situación del país. Quien comete un crimen tiene que sufrir las consecuencias de haberlo hecho. Pero la realidad nunca es tan sencilla. Vivimos en una sociedad cuya configuración produce diariamente decenas de "directos", porque en la base de su estructura la violencia ocupa un lugar privilegiado. Tipificar los diversos modos de manifestación de esta violencia es necesario y útil, pero completamente insuficiente a la hora de pensar una respuesta global; la respuesta integral que la complejidad del problema demanda.

Perfeccionar los modos legales, psicológicos y sociales de tratar cada caso es una tarea de suma urgencia. Está claro que la pregunta: ¿qué hacemos con quienes infringen la ley hoy? es impostergable. Pero ello no debe llevar a pasar por alto la pregunta fundamental: ¿qué hacemos hoy para minimizar las condiciones que favorecen el desarrollo de conductas violentas y delictivas? La primera tarea recae en mayor medida en las instituciones relacionadas con el tratamiento de esos casos - Corte Suprema de Justicia, Ministerio de Justicia, Instituto de protección al menor, etc.-; la segunda nos compete a todos. Es responsabilidad de la sociedad entera decidir si realmente está interesada en erradicar la violencia desde su raíz o prefiere lavarse las manos creyendo que la mayoría nada tenemos que ver con ella.

Carmen Elena Villacorta Zuluaga 